\title{
Efecto de tiempo y temperatura de cocción en chorizo inoculados artificialmente con Listeria monocytogenes
}

\author{
Silvia Nataly Molina-Moreno ${ }^{1}$, Marcela Mercado-Reyes ${ }^{2}$ y Ana K. Carrascal-Camacho ${ }^{1 *}$ \\ ${ }^{1}$ Laboratorio de Microbiología de Alimentos. Grupo de Biotecnología Ambiental e Industrial (GBAI). Facultad de Ciencias. Pontificia \\ Universidad Javeriana. Cra 7 no 43-82, Bogotá Colombia. ${ }^{2}$ Grupo de Enfermedades Infecciosas. Facultad de Ciencias. Pontificia \\ Universidad Javeriana. Cra 7 no 43-82, Bogotá Colombia. \\ *acarrasc@javeriana.edu.co
}

Recibido: 21-08-2008; Aceptado: 26-10-2009

\begin{abstract}
Resumen
Objetivo. Determinar sí los tiempos utilizados por los consumidores para la cocción de chorizos son suficientes para la inactivación de Listeria monocytogenes inoculada artificialmente en este producto. Materiales y métodos. Se realizó una encuesta a 50 amas de casa para preguntar sobre los hábitos de preparación de los chorizos. Se analizaron 60 muestras de chorizos a las que se les inocularon concentraciones de $10^{3} \mathrm{UFC} \mathrm{g}^{-1}$ de un pool de 5 cepas de L. monocytogenes, se aplicaron los procedimientos de cocción indicados por la encuesta y se hizo recuento inmediatamente. Adicionalmente, se realizó una prueba complementaria donde se inocularon 20 muestras de chorizos con poblaciones de $10^{3} \mathrm{UFC} \mathrm{g}^{-1}$ y se sometieron a 72 y $73^{\circ} \mathrm{C}$ durante 30 segundos. Resultados. Mediante la encuesta se logró establecer que 15 minutos de cocción y 5 minutos de fritura es la forma más frecuente de preparación por parte de los consumidores, se logró establecer que el tiempo y las condiciones utilizadas en este ensayo tuvieron un efecto estadísticamente significativo $(0,016)$ sobre la población inoculada. En el ensayo complementario los datos estadísticos (p: 0,0001) indicaron que temperaturas internas de $73^{\circ} \mathrm{C}$ son suficientes para la inactivación de este patógeno a nivel industrial. Conclusión. Tiempos de 15 minutos de cocción y 5 minutos de fritura son suficientes para inactivar concentraciones de $10^{3} \mathrm{~g}^{-1}$ de Listeria monocytogenes inoculadas artificialmente en chorizos.
\end{abstract}

Palabras clave: embutidos crudos, listeriosis, termoresistencia.

\begin{abstract}
Effect of cooking time and temperature on sausages artificially inoculated with Listeria monocytogenes. Objective. To find whether the cooking times traditionally used by consumers are enough to inactivate Listeria monocytogenes artificially inoculated into sausages. Materials and methods. A survey asking about sausage cooking habits was completed with 50 housewives. We analyzed 60 samples of sausages previously inoculated with $10^{3} \mathrm{CFU} \mathrm{g}{ }^{-1}$ from a pool of 5 strains of L. monocytogenes, then the cooking procedures described in the survey were applied to the samples, and counting was done immediately after. Additionally, a complementary test was carried out by inoculating 20 samples of sausages with $10^{3} \mathrm{CFU} \mathrm{g}{ }^{-1}$ and exposing them to $72^{\circ} \mathrm{C}$ and $73{ }^{\circ} \mathrm{C}$ for 30 seg. Results. The survey showed that 15 minute boiling and 5 minute frying are the most frequent ways of preparing sausages by consumers. We established that the time and cooking conditions used in our assay had a statistically significant effect (p: 0.016) on the inoculated samples. In the complementary assay, statistical data (p: 0.0001) indicated that internal temperatures of $73{ }^{\circ} \mathrm{C}$ are enough to inactivate the pathogen at an industrial scale. Conclusion. Cooking by 15 minute boiling and 5 minute frying are enough to inactive concentrations of $10^{3} \mathrm{~g}^{-1}$ of Listeria monocytogenes artificially inoculated into sausages.
\end{abstract}

Key words: listeriosis, raw sausages, thermoresistance. 


\section{Resumo}

Efeito do tempo e temperatura de cozimento em lingüiças inoculadas artificialmente com Listeria monocytogenes. Objetivo. Determinar se o tempo utilizado pelos consumidores para cozinhar lingüiças são suficientes para a inativação de Listeria monocytogenes inoculada artificialmente neste produto. Materiais e métodos. Foram realizadas entrevistas a 50 donas de casa para perguntar sobre os hábitos de preparação das lingüiças. Foram analisadas 60 amostras de lingüiças para as quais foram inoculadas concentrações de $10^{3}$ UFC $\mathrm{g}^{-1}$ de um pool de 5 cepas de L. monocytogenes, foram utilizados procedimentos de cozimento indicados pelas entrevistas e foi feita uma contagem imediatamente. Além disso, foi realizada uma prova complementaria inoculando 20 amostras de lingüiças com populações de $10^{3}$

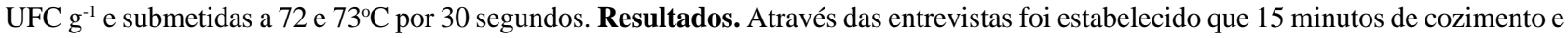
5 minutos de fritura é a forma mais freqüente de preparação por parte dos consumidores, foi estabelecido que o tempo e as condições utilizadas neste estudo foi estatisticamente significativa $(0,016)$ sobre a população inoculada. Na prova complementaria os dados estatísticos $(\mathrm{p}=0,0001)$ indicaram que temperaturas internas de $73^{\circ} \mathrm{C}$ são suficientes para a inativação deste patógeno ao nível da indústria. Conclusão. Tempo de 15 minutos de cozimento e 5 minutos de fritura são suficientes para desativar as concentrações de $10^{3} \mathrm{~g}^{-1}$ de Listeria monocytogenes inoculadas artificialmente em lingüiças.

Palavras-chave: embutidos crudos, listeriose, termoresistência.

\section{Introducción}

Listeria monocytogenes es un microorganismo patógeno transmitido por el consumo de alimentos, especialmente de origen animal (1), el cual puede causar un síndrome conocido como listeriosis, esta enfermedad es de baja ocurrencia, pero tiene una alta tasa de mortalidad (20-30\%) (2). Aunque la listeriosis es una enfermedad relativamente poco común, su gravedad y el hecho de que esté asociada a alimentos de elaboración industrial, especialmente cuando se producen brotes, la sitúan entre las enfermedades transmitidas por alimentos (ETA) de mayor relevancia social y económica (3). La listeriosis se detecta principalmente en los países industrializados, y no se sabe sí las diferencias entre las incidencias en los países desarrollados y en los países en desarrollo se deben a diferencias geográficas verdaderas, a diferentes costumbres alimentarias y medios de conservación de los alimentos, o a diferencias en las prácticas de diagnóstico y notificación (1).

Este microorganismo es reconocido en la industria de alimentos por ser la bacteria Gram positiva no esporulada con mayor termoresistencia (4). Si bien existen diversos métodos para la limitación del crecimiento de L. monocytogenes sólo se ha logrado establecer la eficacia de los procesos térmicos $(1,5)$. En Colombia, el chorizo de acuerdo a la norma técnica colombiana NTC 1325 (sexta actualización), puede ser cocido, crudo y precocido, fermentado o no (6), este varía en su formulación de región en región, a nivel artesanal este producto no es sometido a procesos de cocción y se realizan fermentaciones empíricas que eventualmente no siempre garantizan la ausencia de $L$. monocytogeneses, pues por la naturaleza ubicua de este patógeno puede contaminar el producto durante su elaboración; de otro lado los consumidores realizan diferentes métodos de preparación que dependen de las prácticas pro- pias de cada consumidor, por lo que procesos inadecuados convierten a estos productos en alimentos de alto riesgo. Para evitar este riesgo la industria cárnica realiza procesos de pre-cocción cuyo propósito es reducir la presencia de este patógeno en el producto. Teniendo en cuenta lo anterior se quiso establecer si los tiempos y temperaturas de cocción utilizados por los consumidores son capaces de destruir a L. monocytogenes cuando se inoculan artificialmente en estos productos.

\section{Materiales y métodos}

\begin{abstract}
Aislamientos
Se usaron cinco aislamientos de L. monocytogenes obtenidos de carne de pollo, pertenecientes a la colección del Laboratorio de Microbiología de Alimentos de la Pontificia Universidad Javeriana, caracterizados previamente por PCR en tiempo real (7).
\end{abstract}

\section{Población de estudio y muestra}

La población de estudio fueron: chorizos precocidos provenientes de una fábrica productora de derivados cárnicos, de la ciudad de Bogotá. Se obtuvieron 5 muestras semanales de los productos para un total de 80 muestras. En cada muestreo se trabajo con un mismo lote de producción, escogido al azar. Debe entenderse que cada muestra equivale a la presentación comercial del producto, 8 unidades.

El número de muestras seleccionado se basó en el programa estadístico "tamaño de la muestra" (versión 1.0), teniendo en cuenta que la incidencia de este microorganismo 
es del $14 \%$ en embutidos comercializados en Bogotá (8), con un error tipo I del $5 \%$ y una error tipo II de $20 \%$. El tamaño final obtenido fue de 80 muestras.

\section{Elaboración del banco de células primario (BCP)}

Cada una de las cinco cepas de L. monocytogenes, fueron cultivadas en caldo infusión cerebro-corazón (BHI), suplementado con $0,5 \%$ glucosa, durante 24 horas a $37^{\circ} \mathrm{C}$. A los cultivos se les adicionó glicerol a una concentración final del $10 \%$, posteriormente las suspensiones celulares fueron distribuidas en crioviales en volúmenes finales de $1 \mathrm{ml}$, para un total de 20 viales. Los tubos fueron almacenados a $-70^{\circ} \mathrm{C}$, (9). Se realizó recuento en placa para establecer la población inicial a las 24 horas, en agar Oxford.

\section{Prueba de pureza y viabilidad}

Cada semana durante el estudio se realizó coloración de Gram y recuento en placa en agar Oxford, para verificar pureza y viabilidad.

Elaboración curvas de crecimiento: para las curvas de crecimiento de cada cepa, inicialmente se tomó un criovial proveniente del BCP y se adicionó en $20 \mathrm{ml}$ de caldo BHI, suplementado con glucosa $0,5 \%$, se incubó a $35^{\circ} \mathrm{C}$ durante 18 horas a $120 \mathrm{rpm}$, este inóculo fue añadido a $200 \mathrm{ml}$ de caldo BHI-glucosa $0,5 \%$, se incubó a $35^{\circ} \mathrm{C}$; durante las dos primeras horas se hicieron mediciones a $540 \mathrm{~nm}$ de longitud de onda cada 15 minutos, posteriormente se hicieron las mediciones cada dos horas hasta llegar a la fase estacionaria. Paralelo se hizo recuento en placa. Cada curva se hizo por triplicado (10).

\section{Inoculación de L. monocytogenes en los chorizos}

\section{Preparación del inóculo}

Cada una de las cepas de L. monocytogenes se inoculó en $20 \mathrm{ml}$ de caldo BHI-glucosa $0,5 \%$, se incubaron por 12 horas (fase estacionaria) a $35^{\circ} \mathrm{C}$ a $130 \mathrm{rpm}$. Los cinco cultivos se mezclaron, para obtener un sólo inóculo (11)

Una vez obtenido el inóculo se midió por triplicado la absorbancia (Spectronic 21D), a $540 \mathrm{~nm}$. El cultivo se diluyó con tampón HEPES hasta obtener una absorbancia de 0,25 (equivalente a $10^{8} \mathrm{UFC} \mathrm{ml}^{-1}$ ) (12). A partir de esta concentración se realizaron diluciones seriadas hasta llegar a la concentración de $10^{4}$ microorganismos, esta dilución se utilizó para inocular los chorizos.

\section{Inoculación del producto}

Cada porción de $10 \mathrm{~g}$ de chorizo fue inoculada con un $\mathrm{ml}$ de la dilución $10^{4}$ para obtener una concentración final de $10^{3}$ m.o. $\mathrm{g}^{-1}$; el inóculo se distribuyó en diferentes puntos del producto con el fin de garantizar la homogeneidad, cabe aclarar que cada chorizo se pesó previamente y se inoculó proporcional al peso. Para los ensayos de inactivación térmica se tomaron 4 unidades ( 2 unidades se dejaron sin inocular, controles negativos), 2 unidades se inocularon con $10^{4}$ microorganismos $\mathrm{g}^{-1}$. Una vez inoculados los chorizos, estos se mantuvieron 24 horas en refrigeración antes de iniciar los ensayos de cocción. De cada ensayo se tomó una unidad para recuento inicial y la otra se sometió al proceso de cocción y recuento final. Los recuentos, se realizaron en agar tripticasa de soya suplementado con $6 \mathrm{gL}^{-1}$ de extracto de levadura (TSAYE), adicionado de fosfomicina, terramicina y ceftazidime, como inhibidores de la carga microbiana acompañante. Los controles negativos se sometieron a los procesos descritos anteriormente y se realizaron los recuentos. El total de ensayos realizados fue de 60 .

\section{Tiempos y métodos de cocción de los chorizos}

Para seleccionar el método de cocción y los tiempos utilizados en este estudio se procedió a la realización de una encuesta (n: 50) en la zona noroccidental de Bogotá, entre amas de casas de estratos 3 y 4, donde se estableció que la forma más frecuente de preparación, era cocción en agua durante 15 minutos y posteriormente frito en aceite por 5 minutos. Procedimiento, que se utilizó en este estudio para el proceso de cocción de los chorizos contaminados con $L$. monocytogenes.

Adicionalmente, se realizó un ensayo donde se inocularon 10 muestras de chorizos con $10^{3}$ L. monocytogenes $\mathrm{g}^{-1}$, se sometieron a un proceso de cocción hasta llegar a una temperatura en el centro térmico de $72^{\circ} \mathrm{C}$ y $73^{\circ} \mathrm{C}$ durante $30 \mathrm{seg}$ respectivamente. Se hizo el recuento antes y después de terminado este procedimiento (4).

\section{Análisis estadístico}

Se determinó el recuento antes y después de la cocción con el fin de determinar sí el proceso eliminaba el 100\% 
de los microorganismos inoculados (el valor medio correspondiente en unidades logarítmicas (UL) a $(0,99)$. Para esto se utilizó la prueba t de Student.

\section{Resultados}

\section{Banco de células primario}

Las cinco cepas utilizadas durante el estudio se mantuvieron estables con poblaciones superiores a $10^{8} \mathrm{UFC} \mathrm{g}^{-1}$, al Gram se presentaron como bacilos Gram positivos, no esporulados, cumpliendo con los requisitos de estabilidad propios de un BCP.

\section{Curvas de crecimiento}

En la figura 1 se presentan el promedio de las tres curvas de crecimiento realizadas a cada una de las 5 cepas de L. monocytogenes utilizadas en la investigación. La fase estacionaria estuvo entre las 10-12 horas para las diferentes cepas estudiadas, por tal razón los inóculos que se usaron para contaminar los chorizos se trabajaron con cultivos de 12 horas.

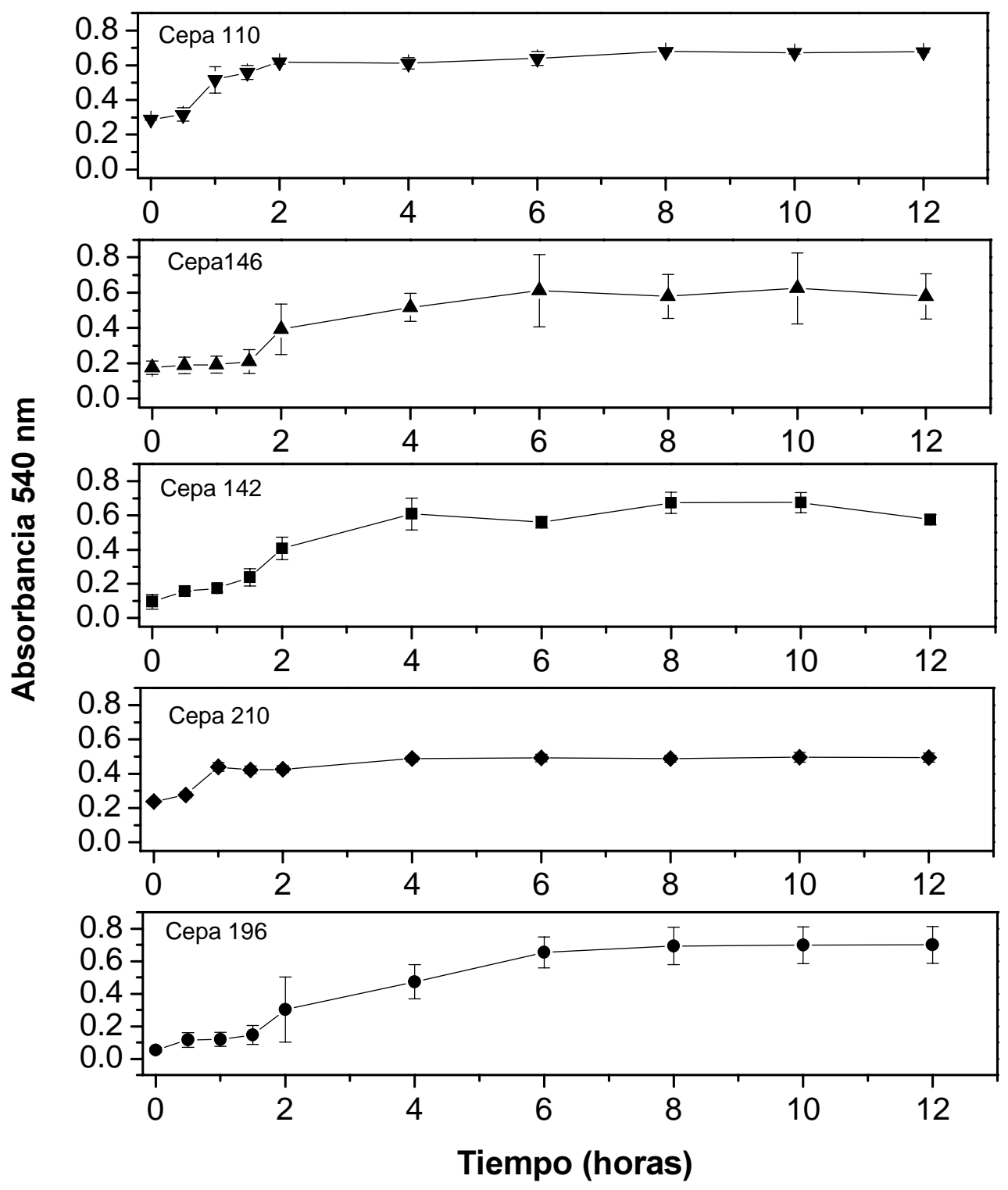

Figura 1. Curvas de crecimiento en caldo BHI suplementado con $0,5 \%(\mathrm{p} / \mathrm{v})$ de glucosa de L. monocytogenes (promedio de las tres réplicas). 


\section{Inactivación térmica}

En la tabla 1, se muestran los promedios de los recuentos de L. monocytogenes en los chorizos, inoculados con $10^{3} \mathrm{UFC} \mathrm{g}^{-1}$, así como de los controles negativos, se presentan las temperaturas finales alcanzadas luego de los correspondientes procesos de cocción y las reducción de unidades logarítmicas (UL) logradas.

El recuento promedio de las muestras inoculadas con $L$. monocytogenes fue de 4,33 UL; en los controles negativos no se evidenció $(<0,99)$ la presencia de este microorganismo, posiblemente por la incorporación de métodos de precocción que se utilizan en la fábrica donde fueron obtenidos los chorizos, indicando que este método reduce el riesgo de presencia de este patógeno en el chorizo. En este estudio una de las muestras inoculadas con L. monocytogenes después del proceso de cocción presentó un recuento 50 m.o. $\mathrm{g}^{-1}$ (1,69 UL), el cual no supera la dosis mínima infectante.

Al realizar los análisis con las 10 réplicas de chorizo, donde se tomaron las muestras a $\operatorname{los} 72^{\circ} \mathrm{C} 4$ de las 10 muestras presentaron recuentos (X: $100 \mathrm{~m} . \mathrm{o} \mathrm{g}^{-1}$ ), en el caso de $73^{\circ} \mathrm{C}$, los recuentos después del proceso fueron $<10 \mathrm{~m} . \mathrm{o} \mathrm{g}^{-1}$.

\section{Medición de la temperatura}

Los chorizos inoculados con $10^{3}$ microorganismos, alcanzaron temperaturas internas que variaron entre $79-93^{\circ} \mathrm{C}$ en las condiciones de cocción seleccionadas, en el caso de la fritura, los chorizos alcanzaron temperaturas internas de $115^{\circ} \mathrm{C}$.

\section{Análisis estadístico}

En el caso de los chorizos inoculados con $10^{3}$ m.o. $\mathrm{g}^{-1}$, se aceptó la hipótesis nula $(\mathrm{p}=0,016)$ indicando que tiempos de cocción de 15 minutos y 5 minutos de fritura son suficientes para reducir la población de L. monocytogenes inoculada en los chorizos estudiados.

Con relación a los chorizos donde se aplicaron temperaturas de 72 y $73^{\circ} \mathrm{C}$ de manera constante durante 30segundos, se encontró que la hipótesis se cumple cuando se llega a $73^{\circ} \mathrm{C}$, con un $\mathrm{p}<0,001$, en el caso de $72^{\circ} \mathrm{C}$ se obtuvo un $\mathrm{p}$ : 0,28 , indicando que no se encontraron diferencias entre las poblaciones inoculadas antes y después del tratamiento de cocción.

\section{Discusión}

Teniendo en cuenta que un banco de células es un conjunto de alícuotas homogéneas de un cultivo microbiológicamente puro que se almacena bajo condiciones que garanticen su viabilidad, en este estudio se lograron mantener las condiciones anteriormente descritas asegurando la calidad de los inoculos utilizados en los estudios de inactivación térmica (9).

Con relación a las curvas de crecimiento de L. monocytogenes, el caldo BHI suplementado con glucosa al $0.5 \%(\mathrm{p} / \mathrm{v})$ fue apropiado ya que las cepas de L. monocytogenes, presentaron un rápido crecimiento, su fase logarítmica se obtuvo para las cepas entre la hora 2 y 8 , se observó un enturbiamiento mayor en la parte inferior concordando con los datos de Buchanan \& Klawitter (13) quienes señalan que este microorganismo crece mejor con tensiones de oxígeno menores que las del aire. Así mismo, el elevado contenido de nutrientes del caldo $\mathrm{BHI}$ favoreció el rápido crecimiento de este patógeno, permitiéndole mantener características de antigenicidad, virulencia, toxicidad y termoresistencia $(4,14)$. Los datos de las curvas obtenidas para cada una de las cepas estudiadas concuerdan con estudios previos, donde se usaron las mismas condiciones de este estudio. No obstante difieren, de los resultados obteTabla1. Temperatura final de los chorizos inoculados con $10^{3} \mathrm{UFC} / \mathrm{g}$ y destrucción de L. monocytogenes
después del proceso de cocción

\begin{tabular}{lcccc}
\hline Alimento & Rto inicial $\left(\mathbf{U L ~}^{-1}\right)$ & Rto final $\left(\mathbf{U L ~}^{-1}\right)$ & $\mathbf{X}$ Temp. final $\left({ }^{\circ} \mathbf{C}\right)$ & $\begin{array}{c}\text { Reducción } \\
(\mathbf{U L ~ i n i c i a l / U L ~ f i n a l ~})\end{array}$ \\
\hline Ensayos & 4,43 & 1,01 & 86,37 & 3,42 \\
Controles & $<0,99$ & $<0,99$ & 85,91 & 0 \\
\hline
\end{tabular}

n: 60 
nidos por Pagan et al., 1997(11), quienes reportaron la fase estacionaria a las 24 horas de incubación. Estos datos podrían estar asociados a que estos autores utilizaron el caldo BHI, sin suplementar con glucosa al $0,5 \%$, por lo que la tasa de duplicación fue menor a la obtenida en esta investigación, debido a que la glucosa permite una mayor tasa de crecimiento al ser un azúcar simple. Adicionalmente, al haber usado la misma temperatura de incubación para el inoculo y la curva de crecimiento, se logró un proceso previo de adaptación por parte de las cepas, concordando con datos de Gay et al, 1996, quienes encontraron que realizar los inóculos a $30-37^{\circ} \mathrm{C}$ propician curvas de crecimiento en menor tiempo (15). El inóculo utilizado para contaminar artificialmente los chorizos siempre estuvo en fase estacionaria ya que se ha demostrado que este microorganismo es más resistente al estrés térmico en esta fase de crecimiento (14).

Con la encuesta "hábitos de preparación de embutidos" se logró establecer que el 46,9\% de las amas de casa preparan los chorizos con 15 minutos de cocción y 5 de fritura, este procedimiento fue replicado en el laboratorio, para simular las condiciones de los consumidores. Durante el estudio se pudo observar una variación en los cambios de temperatura del centro térmico $\left(79-93^{\circ} \mathrm{C}\right)$ del chorizo, estos resultados pueden estar relacionados con la estructura del chorizo, ya que este no es una emulsión homogénea, adicionalmente se encuentran ingredientes como los condimentos que están dispersos dentro del chorizo que pueden afectar los procesos de transporte calórico dentro del producto, por lo que no se puede asegurar la uniformidad en la trasferencia de calor, esto puede ser propicio para que L. monocytogenes desarrolle resistencias subletales al calor, permitiéndole expresar proteínas del choque térmico, mecanismo que no ha logrado esclarecerse totalmente para este microorganismo (14). Se ha demostrado que las bacterias pueden aumentar la resistencia al calor cuando son expuestas a temperaturas medias por tiempos cortos de cocción (16), en el caso de esta investigación al tenerse los chorizos durante 15 minutos en cocción y 5 minutos en fritura, se puede evitar la resistencia al calor, permitiendo la inactivación de este microorganismo. Cabe aclarar que las temperaturas del centro térmico en los chorizos no se mantuvieron constantes, bajando y subiendo de manera irregular, por lo que no pueden compararse con los procesos elaborados industrialmente los cuales son controlados.

La resistencia al calor por parte de L. monocytogenes está influenciada por muchos factores tales como el tipo de cepa, las condiciones previas de crecimiento, la presencia de ácidos, condiciones de estrés, tipo de alimento, así como el tipo de diseño experimental que se realiza (17). Se ha señalado que existe una variación en el valor D para cepas de Listeria, que pueden estar asociadas al medio de recuperación después del choque térmico, corroborándose uno de los principios de la teoría probabilística el cual postula que "en un cultivo puro existe una heterogeneidad entre las células" (18), esto podría explicar que en una de las muestras inoculadas se logró la recuperación de 50 microorganismos, pues en este ensayo se trabajo con medios no selectivos que aumentan la posibilidad de recuperar células lesionadas, también pueden estar asociadas con los componentes de los medios de cultivos, ya que algunos de estos (por ejemplo la betaína), pueden proteger del daño térmico por la estabilización de membranas y otras estructuras, o por estimular la producción de proteínas de choque térmico (19). En este estudio se utilizo caldo BHI, el cual es rico en betaína y carnitina (16) favoreciendo la termoresistencia de las cepas estudiadas. De otro lado, la temperatura de crecimiento del inóculo afecta la biosíntesis de lípidos, la composición de las membranas, así como la síntesis de proteínas (14), siendo más resistentes aquellas que se cultivan a temperaturas altas (11), en esta investigación el inóculo se trabajó a $37^{\circ} \mathrm{C}$, temperatura que favorece la termoresistencia de Listeria.

Otro factor a tener en cuenta son las condiciones de la prueba de termoresistencia, se ha demostrado que este microorganismo es más resistente cuando el estudio se hace sobre los alimentos que en medios de cultivo de laboratorio, así como la forma de inoculación del patógeno y la concentración de este (14). Las células de L. monocytogenes que se han sometido previamente a procesos de refrigeración o congelación son más resistentes al calor, siendo este un factor muy importante en alimentos refrigerados que tienen recalentamientos posteriores (20). Las condiciones de recuento varían de un estudio a otro, en especial con el tipo de medio y los inhibidores que se utilizan para lograr la recuperación de L. monocytogenes, estos últimos afectan la tasa de recuperación, ya que inducen injuria bacteriana (4). También se ve afectada por las concentraciones de gases, siendo desfavorable las condiciones aeróbicas. Por lo anterior todos estos datos, deben considerarse cuando se hacen revisiones de los valores D de Listeria ya que son muy difíciles de reproducir cuando se varía alguna condición.

Se ha señalado que un proceso adecuado de cocción en carnes y derivados cárnicos, puede destruir a L. monocytogenes, donde la efectividad del proceso térmico está relacionada con las características propias de la carne (por ejemplo contenido de grasa, edad de la carne, Aw, agentes antimicrobianos entre otros) (4). Con relación a la edad de la carne, entre más fresca sea, los valores D para L. monocytogenes son más altos, la razón posiblemente sea la formación de óxidos tóxicos a partir de lípidos durante el 
almacenamiento. Se ha estudiado que la termoresistencia puede variar con el tipo de alimento. En este estudio no se realizó ningún choque térmico posterior al proceso de cocción, ya que el chorizo en sus prácticas de preparación, no se enfría antes de su consumo si no por el contrario se mantiene caliente. De otro lado, factores extrínsecos como la cantidad de agua utilizada para la cocción de los chorizos, la temperatura de esta (en el estudio se mantuvo en $92^{\circ} \mathrm{C}$ ) y el momento en que se adicionan los chorizos generan cambios que pueden afectar los datos obtenidos en el laboratorio, cabe aclarar que en los alimentos sólidos (como los chorizos estudiados), cuando la transferencia por calor es baja puede generar gradientes de temperaturas que incrementan la resistencia de L. monocytogenes durante el proceso de cocción (14). También influye la velocidad con la cual son calentadas las células por ejemplo Kim et al (1994), inocularon carne de cerdo (materia prima de los chorizos); cuando estos se calentaron lentamente (1,3 $\left.{ }^{\circ} \mathrm{Cmin}^{-1}\right)$, las células de L. monocytogenes mostraron mayor termoresistencia (valor $\mathrm{D}_{60}: 9,2$ ) que células calentadas a $8.0^{\circ} \mathrm{C} / \mathrm{min}$ (valor $\mathrm{D}_{60} 5,5$ ). En esta investigación se pudo determinar que los chorizos aumentaban en promedio $5,1^{\circ} \mathrm{C} \mathrm{min}^{-1}$, siendo este un calentamiento intermedio lo que favorecería la inactivación de listeria en este producto (21).

Como se mencionó previamente, la formulación de los chorizos varía de región en región, no obstante existen un número de sustancias con efecto antimicrobiano que la norma NTC 1325, permite adicionar a este producto y que pueden tener un efecto inhibitorio sobre L. monocytogenes, dentro de los que se incluyen, el nitrito de sodio, el ácido ascórbico, ácido láctico, lactato de sodio y eritorbato de sodio. El nitrito de sodio en los chorizos, según la (NTC) 1325 , no puede superar las $200 \mathrm{ppm}$ residuales en producto en proceso, incluyendo la dosificación de ácido ascórbico, eritorbato o ascorbato de sodio o los tres. Se ha propuesto que el nitrito de sodio puede ser listeriostático cuando se usa en conjunto con un bajo pH, aumento de cloruro de sodio, temperaturas de refrigeración y condiciones anaeróbicas que simulan el empaque al vacío, condiciones similares a las de este estudio. El lactato de sodio puede tener un efecto listeriostático cuando se usa en concentraciones que varían de $2-4 \%$, se sabe que esta sustancia actúa mejor cuando se combina con cloruro de sodio y acetato de sodio (22). Se ha determinado que cuando se adicionaron al cerdo molido $2 \%$ de cloruro de sodio, $1 \%$ de glucosa, $0,4 \%$ de fosfatos de sodio, $0,055 \%$ de eritorbato de sodio y $0,0156 \%$ de nitrito de sodio, el efecto protectivo aumenta, destruyendo 3,8 log UFC g-1 . De ahí la importancia que tienen estas sustancias en la formulación de este tipo de productos para reducir el riesgo de contaminación con este patógeno
Los factores anteriormente descritos pueden estar relacionados con que en una de las sesenta muestras del estudio después del proceso de cocción se presentó un bajo recuento de Listeria, cabe aclarar que la concentración de microorganismo obtenida no superó la dosis mínima infectante (100 m.o) (1), concordando con datos de Doyle et al (2001), quien asegura que los métodos convencionales de cocción no siempre destruyen a Listeria. Partiendo de estos resultados y teniendo en cuenta que Yen et al. 1991, logró establecer que temperaturas internas de 73,8 ${ }^{\circ} \mathrm{C}$, lograban destruir de 4,0-5,5 UL de L. monocytogenes, se procedió a realizar 2 ensayos donde se inocularon concentraciones de $10^{3} \mathrm{UFC} \mathrm{g}^{-1}$ de L. monocytogenes en chorizos, donde se mantuvo durante un minuto temperaturas internas de $72^{\circ} \mathrm{C} \mathrm{y} 73^{\circ} \mathrm{C}$ respectivamente, cada ensayo tuvo 10 réplicas, estos resultados demostraron que $73^{\circ} \mathrm{C}$, son suficientes para destruir este patógeno en los chorizos estudiados, señalando que los procesos de cocción controlados logran inactivar este microorganismo en las concentraciones inoculadas.

Estos datos sugieren la necesidad de realizar ensayos complementarios donde se evalúen otros factores como grosor del chorizo y velocidad de transferencia del calor que no fueron considerados en este estudio.

\section{Conclusiones}

Se logró establecer que la forma más utilizada por los consumidores para la cocción de chorizos es la cocción en agua durante 5 minutos y la posterior fritura en sartén Tiempos de 15 minutos de cocción y 5 minutos de fritura son suficientes para reducir poblaciones de $10^{3}$ células de Listeria monocytogenes inoculada artificialmente en chorizos.

Temperaturas internas de $73^{\circ} \mathrm{C}$ durante un minuto son suficientes para destruir poblaciones de $10^{3}$ de Listeria monocytogenes.

\section{Financiación}

Este proyecto fue financiado por la Vicerrectoría Académica de la Pontificia Universidad Javeriana. Proyecto \#: 00000221

\section{Conflicto de intereses}

Los autores expresan no tener conflictos de intereses relacionados con este trabajo 


\section{Referencias}

1. FAO/OMS. World Health Organization/Food and Agriculture Organization of the United Nation. Risk assessment of Listeria monocytogenes in ready-to-eat foods. Technical report. Microbiological risk assessment series 5. Rome, Italy. 2004; 269.

2. Vazquez-Boland J, Kuhn M, Berche P, Chakraborty T, Domínguez-Bernal G, Goebel W, González-Zorn B, Wehland J, Kreft J. Listeria Pathogenesis and Molecular Virulence Determinants. Clinical Microbiology Reviews 2001; 14(3): 584-640.

3. Roberts $\mathrm{T} \&$ Pinner R. Economic impact of disease caused by L. monocytogenes en: Miller, Smith y Somkuti. 1990, 137-149.

4. Doyle M, Mazzotta A, Wang T, Wiseman D, Scott V. Heat resistance of Listeria monocytogenes. Journal of Food Protection 2001; 64 (3): 410-429.

5. Food Safety Authority of Ireland (FSAI). The control of management of Listeria monocytogenes. Contamination of food. Dublin, Ireland. 2005; 95.

6. ICONTEC. Norma técnica 1325, sexta actualización. Industrias alimentarias Productos cárnicos procesados no enlatados. Bogotá, Colombia. 2008: 5.

7. Carrascal AK, Correa C, Fonseca J. Detección de Listeria monocytogenes en expendios de pollo procesado en la zona suroccidental de Bogotá, D.C. Laboratorio actual 2007; 23 (40): 29-32.

8. Ramírez LJ \& Urquijo G.A. Inspección, Vigilancia y Control de las Carnes de Bovinos y Porcinos en Bogotá, D.C. Boletín Epidemiológico Distrital 2002; 7(5): 2-11.

9. Mesa R.A, Monroy A.F, Mercado M, Poutou, R.A, Rodriguez P, Pedroza AM. Study in real time of cryopreserved strain banks. Universitas Scientarium 2004; 9(2): 35-42

10. Casadiego P, Cuartas R, Mercado M, Díaz M, Carrascal A.K. Effectiveness of electrolyzed oxidizing water for inactivating Listeria monocytogenes in lettuce. Universitas Scientiarum 2005; 10(1): 97-108.

11. Pagán R, Condón S, Sala F. Effect of several factors on the heat-shock-induced thermotolerance of Listeria monocytogenes. Applied and Environmental Microbiology 1997; 63: 3225-3232.

12. Gill, A, Holley, R. Mechanisms of Bacterial Action of Cinnamaldehyde against Listeria monocytogenes and
Eugenol against L. monocytogenes and Lactobacillus casei. Applied and Enviromental Microbiology 2004; 70 (10): 5750-5755

13. Buchanan R, Klawitter L. Effects of Temperature and Oxygen on the Growth of Listeria monocytogenes at pH 4.5. Journal of Food Science 1990; 55: 1754-1756.

14. Sergelidis D, Abrahim A. Adaptative response of Listeria monocytogenes to heat and its impact on food safety. Food Control 2009; 20: 1-10.

15. Gay M, Cerf O, Davey KR. Significance of pre-incubation temperature and inoculum concentration on subsecuent growth of Listeria monocytogenes at $14^{\circ} \mathrm{C}$. Journal of Bacteriology 1996, 96: 433-438.

16 Lynn R. The control, survival and growth of Listeria monocytogenes on food products. Dissertation for Doctor of Philosophy. The Ohio State University. 2004: 13

17. Lyn YD \& Chou, CC. Effect on heat shock on thermal tolerance and susceptibility of Listeria monocytogenes to other environmental stresses. Food Microbiology 2004; 21: 605-610.

18. Vab Boekel M. On the use of the Weibull model to describe thermal inactivation of microbioal vegetative cells. International Journal of Food Protection 2002; 74: 139-159.

19. Schultze KK, Linton RH, Cousin MA, Luchansky JB, Tamplin, ML Effect of preinoculation growth media and fat levels on thermal inactivation of a serotype $4 b$ strain of Listeria monocytogenes in frankfurter slurries. Food Microbiology 2007; 24: 352-61.

20. Novak JS, Junefa VK. Effect of refrigeration or freezing on survival of Listeria monocytogenes Scott A in undercooked ground beef. Food Control 2003; 14(1): 25-35.

21. Kim K, Schmitidt R, Phebus, Olson. Heating and storage conditions affect survival and recovery of Listeria monocytogenes in ground pork. Journal Food Science 1994; 59: 30-32.

22. Mbandy E, Shelef F. Enhanced inhibition of Listeria monocytogenes and Salmonella Enteritidis in meat by combinations of sodium lactate and diacetate. Journal of Food Protection 2001; 64: 690-694.

23. Ollinger.Snyder P, El-Gazzar F, Matthews E, Marths H, Unklesbay D. Thermal destruction of Listeria monocytogenes in ground pork prepared with and without soy hulls. Journal of Food Protection 1995: 58: $573-576$. 